\title{
Experiência paterna no primeiro ano de vida da criança: revisão integrativa de pesquisas qualitativas
}

\section{Paternal experience during the child's first year of life: integrative review of qualitative research}

Fernando Henrique Ferreira ${ }^{1}$, Monika Wernet ${ }^{2}$, Bruna de Souza Lima Marski ${ }^{3}$, Graziani Izidoro Ferreira ${ }^{4}$, Laura Priscila Navarrete de Toledo ${ }^{5}$, Márcia Regina Cangiani Fabbro ${ }^{6}$

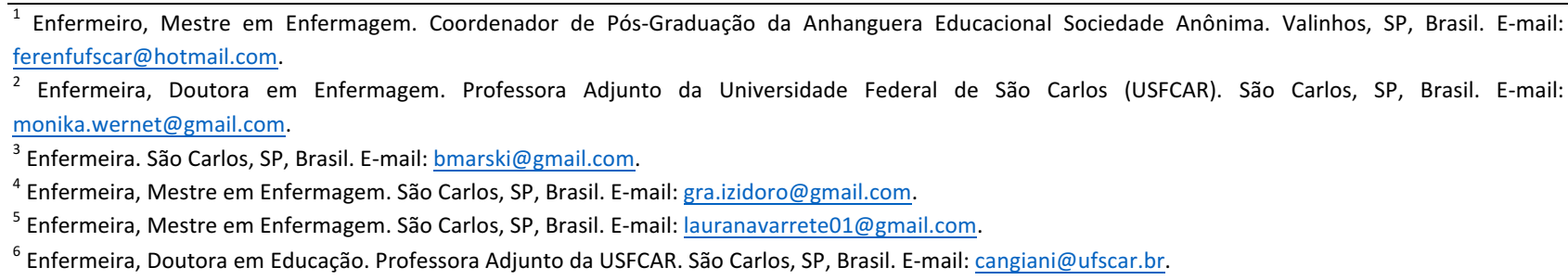

\section{RESUMO}

As transformações sociais têm suscitado a reflexão sobre o papel paterno e apontado para novas paternidades, caracterizadas pelo envolvimento mais efetivo do pai no cotidiano familiar e nos cuidados com a criança. A presente revisão integrativa de pesquisas qualitativas teve como objetivo sintetizar as evidencias da literatura sobre a experiência paterna ao longo do primeiro ano de vida da(o) filha(o), com atenção às questões de gênero. Vinte e três artigos integram este estudo. Observou-se que os pais vivenciaram interações positivas com seus bebês e, ainda, almejaram mais tempo e espaço para se dedicarem à família. No entanto, a desigualdade entre os gêneros, a contínua exigência da provisão financeira do lar e sua inaptidão para o momento da amamentação impediram que houvesse maior envolvimento paterno. Concluiu-se que o movimento das novas paternidades faz-se presente na vivência do pai e as tendências contemporâneas de gênero são desafios no apoio à parentalidade.

Descritores: Paternidade; Relações Pai-Filho; Identidade de Gênero; Enfermagem Pediátrica; Saúde do Homem.

\begin{abstract}
Social transformations have raised reflection about the paternal role and pointed to new fatherhoods, characterized by more effective involvement of the father in the family routine and in childcare. The present integrative review of qualitative studies aimed to synthetize the literature evidence about fatherhood experience throughout the first year of the child's life, attentive to gender questions. Twenty three studies integrated this review. It was observed that fathers had positive experience with their babies and, still, craved for more time and space to dedicate to the family. However, inequality between genders, continuous requirement of financial provision at home and their inaptitude for breastfeeding moment impeded more paternal involvement. We concluded that new fatherhoods movement is present in the father experience and contemporary gender tendencies are challenges for parenting support.
\end{abstract}

Descriptors: Paternity; Father-Child Relations; Gender Identity; Pediatric Nursing; Men's Health. 


\section{INTRODUÇÃO}

$\mathrm{Na}$ contemporaneidade, novos modelos familiares, distintos do tradicional, são resultantes de movimentos sociais, sobretudo o feminismo, com transformações nas relações de gênero e nos modos de ser família. Assim, tornou-se um desafio a coexistência temporal destes modelos e o predomínio do imaginário coletivo da família tradicional $^{(1)}$.

Os papéis parentais sofrem as consequências deste processo e o cuidado da criança, um dos papéis da família, fica na dependência dos sujeitos nela envolvidos e nas particularidades que estes atribuem as questões de gênero em suas práxis ${ }^{(2)}$. Neste contexto, a gestação e o cuidado da criança sempre foram atributos da mulher, com tendência a distanciar o homem deles ${ }^{(2-3)}$. Tal fato reforça as colocações de Elisabeth Badinter ${ }^{(4)}$ ao questionar o mito do amor materno como inato à mulher, remetendo-o como uma construção social de ser natural e instintivo, enquanto, o amor paterno de ser opcional, a ser concretizado ou não(5).

Este cenário, vem ampliando discussões acerca da inclusão do homem nas questões de saúde, sexualidade e reprodução, com vistas a igualdade entre os gêneros ${ }^{(5-7)}$. Em paralelo, grupos de homossexuais e homens prófeministas passaram a questionar a reprodução do modelo de masculinidade tradicional e hegemônico, bem como promoverem reflexão sobre a formação da identidade masculina propondo novas formas de ser homem, novas masculinidades ${ }^{(5,8)}$. Seguindo essa tendência, identificam-se avanços no debate acerca das novas paternidades, entendidas como uma participação efetiva dos homens no cotidiano familiar, inclusive no cuidado da criança $^{(9)}$.

Diante destes apontamentos e considerando os questionamentos acerca do modelo tradicional de masculinidade e paternidade e as novas conformações familiares e a necessidade de acolhimento às novas paternidades, este estudo teve como objetivo sintetizar as evidências da literatura sobre a experiência paterna ao longo do primeiro ano de vida da(o) filha(o), com atenção às questões de gênero.

\section{MÉTODO}

Evidências qualitativas trazem descrições densas e de profundidade contribuindo para o objetivo deste estudo, que está centrado na questão de pesquisa: que repercussões as relações de gênero trouxeram à paternidade? Assim, optou-se por uma revisão integrativa de pesquisas qualitativas, método que agrega conhecimentos produzidos por pesquisas qualitativas primárias ${ }^{(10-11)}$, seguindo as etapas preconizadas por Whittemore e Knalf ${ }^{(10)}$.

A primeira etapa foi a seleção das bases de dados, o estabelecimento de descritores, critérios de inclusão e de exclusão. As buscas foram realizadas nos seguintes repositórios: Cumulative Índex to Nursing and Allied Health Literature (CINAHL); Literatura Latino-americana e do Caribe em Ciências da Saúde (LILACS); Medical Literature and Retrieval System On Line (MedLINE); SocINDEX; e Education Resources Information Center (ERIC). Estas plataformas veiculam artigos condizentes com o problema em foco e são atualizadas periodicamente.

Os descritores adotados foram: pai, paternidade, relação pai-filho, saúde, identidade de gênero e educação com suas respectivas versões em inglês. Eles foram combinados em trios a partir das lógicas boleanas and e or, fixando os dois primeiros termos unidos pela lógica or e o terceiro por meio da lógica and. Exemplo: pai or paternidade and educação.

Os seguintes critérios de seleção foram empregados: ser artigo científico original de abordagem exclusivamente qualitativa; ter resumo disponível on-line; estar disponível gratuitamente on-line na íntegra; estar escrito em inglês, português ou espanhol; estar sua publicação entre janeiro de 2003 e dezembro de 2014; veicular conhecimento acerca da paternidade entre o nascimento do filho e o primeiro ano de vida deste; e ter como sujeito da pesquisa o pai. 
Os artigos foram excluídos quando não possuíam o caminho metodológico claramente descrito e/ou exploravam temáticas que problematizavam particularidades à vivência da paternidade, como por exemplo: violência, adoção, encarceramento, dependências químicas, adolescência, não coabitação com o(s) filho(s), dentre outros.

A seleção inicial ocorreu a partir da leitura dos títulos e resumos e, no aparente atendimento ao estudo, sendo lidos na íntegra por dois pesquisadores apoiados em um protocolo de avaliação e análise dos dados das pesquisas primárias. Este orientava a análise: da identificação bibliográfica da pesquisa, do objetivo, dos sujeitos, do método, da forma de análise de dados e dos resultados relacionados ao fenômeno em foco. Após leitura, os artigos eram discutidos em reunião entre os pesquisadores, sendo selecionados os de concordância do grupo. Na dúvida de inclusão, uma nova dupla de pesquisadores realizava a leitura para a tomada de decisão acerca de sua inclusão.

O processo analítico ocorreu por meio de leituras reiterativas na íntegra dos artigos, quando se identificou nos resultados e discussões, conhecimentos que respondessem a pergunta de pesquisa e o objetivo da presente revisão. A síntese do material foi feita buscando a integração dos dados entre si, ao avaliar repetições, complementaridades e articulações dos conhecimentos.

\section{RESULTADOS E DISCUSSÃO}

O processo de busca e seleção dos artigos pode ser observado no Quadro 1.

Apesar de terem sidos selecionados um total de 32 artigos, nove deles foram selecionados de forma duplicada, portanto, 23 artigos integram esta revisão. As informações referentes aos artigos estão disponíveis no Quadro 2.

Quadro 1: Número de referências obtidas por bases de dados de acordo com descritores adotados e o número de referências selecionadas. São Carlos, SP, Brasil, 2015.

\begin{tabular}{|c|c|c|c|c|}
\hline $\begin{array}{l}\text { Base de } \\
\text { Dados }\end{array}$ & Descritores & $\begin{array}{l}\text { Número de } \\
\text { referências obtidas }\end{array}$ & $\begin{array}{l}\text { Número de } \\
\text { artigos lidos }\end{array}$ & $\begin{array}{l}\text { Número de artigos } \\
\text { selecionados }\end{array}$ \\
\hline CINAHL & $\begin{array}{c}\text { Father or Fatherhood and } \\
\text { Gender/Education/Health/Father-Child Relations }\end{array}$ & 714 & 16 & 4 \\
\hline LILACS & $\begin{array}{l}\text { Pai or Paternidade and Identidade de } \\
\text { gênero/Educação/Saúde/Relação pai-filho }\end{array}$ & 155 & 23 & 15 \\
\hline MedLINE & $\begin{array}{c}\text { Father or Fatherhood and } \\
\text { Gender/Education/Health/ Father-Child Relations }\end{array}$ & 1409 & 26 & 8 \\
\hline SocINDEX & $\begin{array}{c}\text { Father or Fatherhood and } \\
\text { Gender/Education/Health/ Father-Child Relations }\end{array}$ & 1360 & 28 & 5 \\
\hline ERIC & $\begin{array}{c}\text { Father or Fatherhood and } \\
\text { Gender/Education/Health/ Father-Child Relations }\end{array}$ & 41 & 2 & 0 \\
\hline & Total & 3679 & 90 & 32 \\
\hline
\end{tabular}


Quadro 2: Quadro síntese dos artigos integrantes da revisão por autor(es)/ano e país, foco do estudo, sujeitos e método em ordem cronológica de publicação. São Carlos, SP, Brasil, 2015.

\begin{tabular}{|c|c|c|c|}
\hline $\begin{array}{l}\text { Autor(es) / Ano / País } \\
\text { do estudo }\end{array}$ & Foco do estudo & Sujeitos & Método \\
\hline $\begin{array}{l}\text { Henwood; Procter / } \\
2003 \text { / Inglaterra }\end{array}$ & $\begin{array}{l}\text { Expectativas de homens em relação à paternidade frente as } \\
\text { transformações sociais. }\end{array}$ & Trinta pais primíparos britânicos. & Entrevista semiestruturada. \\
\hline $\begin{array}{c}\text { Bustamante / } 2005 / \\
\text { Brasil }\end{array}$ & $\begin{array}{l}\text { As vivências em torno da paternidade e os nexos destas com discursos } \\
\text { e práticas do pai. }\end{array}$ & Sete pais brasileiros de crianças pequenas. & $\begin{array}{l}\text { Estudo exploratório etnográfico, observação } \\
\text { participante e entrevista semiestruturada. }\end{array}$ \\
\hline $\begin{array}{l}\text { Bustamante; Trad / } \\
2005 \text { / Brasil }\end{array}$ & $\begin{array}{l}\text { O envolvimento do pai de camadas populares nos cuidados em saúde } \\
\text { de crianças pequenas. }\end{array}$ & $\begin{array}{l}\text { Seis famílias brasileiras com crianças } \\
\text { pequenas. }\end{array}$ & $\begin{array}{l}\text { Estudo etnográfico, observação participante e } \\
\text { entrevista. }\end{array}$ \\
\hline $\begin{array}{l}\text { Brito; Oliveira / } 2006 \text { / } \\
\text { Brasil }\end{array}$ & A opinião do homem-pai acerca da amamentação. & $\begin{array}{l}\text { Treze pais brasileiros com filhos na faixa } \\
\text { etária de } 0 \text { a } 24 \text { meses em aleitamento } \\
\text { materno. }\end{array}$ & $\begin{array}{l}\text { Entrevistas semiestruturadas, análise de } \\
\text { conteúdo temática de Bardin. }\end{array}$ \\
\hline $\begin{array}{l}\text { Freitas; Coelho; Silva / } \\
\quad 2007 \text { / Brasil }\end{array}$ & $\begin{array}{l}\text { A ocorrência do sentimento de paternidade, as responsabilidades e o } \\
\text { significado que a experiência paterna conferiu ao homem no espaço } \\
\text { doméstico. }\end{array}$ & $\begin{array}{l}\text { Dez pais brasileiros, cujos filhos eram } \\
\text { atendidos em um hospital escola. }\end{array}$ & $\begin{array}{l}\text { Entrevista semiestruturada, enfoque teórico de } \\
\text { gênero. }\end{array}$ \\
\hline $\begin{array}{l}\text { Silva; Piccinini / } 2007 \text { / } \\
\text { Brasil }\end{array}$ & $\begin{array}{l}\text { Os sentimentos relacionados à paternidade e o envolvimento } \\
\text { paterno. }\end{array}$ & Três pais brasileiros. & $\begin{array}{c}\text { Estudo de casos coletivos, entrevista } \\
\text { semidirigida, análise de conteúdo temática de } \\
\text { Bardin. }\end{array}$ \\
\hline $\begin{array}{l}\text { Bucher-Maluschke / } \\
2008 \text { / Brasil }\end{array}$ & $\begin{array}{l}\text { O sentido atribuído por pais cuidadores à vivência da paternidade e à } \\
\text { masculinidade. }\end{array}$ & $\begin{array}{l}\text { Seis pais brasileiros que vivenciavam a } \\
\text { paternidade de uma forma participativa }\end{array}$ & $\begin{array}{l}\text { Estudo exploratório, grupo focal, análise das } \\
\text { práticas discursivas, construcionismo social. }\end{array}$ \\
\hline $\begin{array}{l}\text { Fägerskiöld / } 2008 \text { / } \\
\text { Suécia }\end{array}$ & $\begin{array}{l}\begin{array}{l}\text { As experiências de pais primíparos durante a primeira infância de seus } \\
\text { filhos. }\end{array}\end{array}$ & Vinte pais primíparos brasileiros. & Teoria fundamentada nos dados. \\
\hline $\begin{array}{l}\text { Pontes; Alexandrino; } \\
\text { Osório / } 2008 \text { / Brasil }\end{array}$ & $\begin{array}{l}\text { As vivências, os conhecimentos, os comportamentos e os sentimentos } \\
\text { do pai acerca do processo de amamentação. }\end{array}$ & $\begin{array}{l}\text { Dezessete pais brasileiros, cujos filhos } \\
\text { tinham idade entre } 6 \text { e } 8 \text { meses. }\end{array}$ & $\begin{array}{l}\text { Estudo descritivo, método da análise de } \\
\text { conteúdo temática de Bardin. }\end{array}$ \\
\hline $\begin{array}{l}\text { Freitas et al. / } 2009 \text { / } \\
\text { Brasil }\end{array}$ & Os significados atribuídos à paternidade por homens que são pais. & $\begin{array}{l}\text { Dez pais brasileiros, cujos filhos eram } \\
\text { atendidos em um hospital escola. }\end{array}$ & $\begin{array}{c}\text { Entrevista semiestruturada, enfoque teórico de } \\
\text { gênero. }\end{array}$ \\
\hline $\begin{array}{c}\text { Pontes; Osório; } \\
\text { Alexandrino / 2009 / } \\
\text { Brasil }\end{array}$ & $\begin{array}{l}\text { Opiniões de homens sobre a participação do pai durante a } \\
\text { amamentação. }\end{array}$ & Onze pais brasileiros. & $\begin{array}{l}\text { Estudo descritivo, análise de conteúdo temática } \\
\text { de Bardin. }\end{array}$ \\
\hline $\begin{array}{l}\text { Krob; Picinini; Silva / } \\
\quad 2009 \text { / Brasil }\end{array}$ & $\begin{array}{l}\text { As expectativas e os sentimentos do pai sobre a transição para a } \\
\text { paternidade a partir de sua experiência entre a gestação e o } \\
\text { nascimento dos bebês. }\end{array}$ & Vinte pais primíparos brasileiros. & $\begin{array}{l}\text { Estudo descritivo, entrevista, análise de } \\
\text { conteúdo temática de Bardin. }\end{array}$ \\
\hline $\begin{array}{c}\text { Oliveira; Brito / } 2009 \text { / } \\
\text { Brasil }\end{array}$ & $\begin{array}{l}\text { As ações desenvolvidas pelo pai durante o puerpério de sua } \\
\text { companheira. }\end{array}$ & $\begin{array}{l}\text { Quinze pais brasileiros que coabitavam } \\
\text { com suas esposas no período puerperal. }\end{array}$ & $\begin{array}{l}\text { Entrevista semiestruturada, Interacionismo } \\
\text { Simbólico, análise de conteúdo. }\end{array}$ \\
\hline Miller / 2010 / Inglaterra & A transição para a paternidade de pais primíparos. & Dezessete pais britânicos. & $\begin{array}{l}\text { Estudo longitudinal, entrevista, análise de dados } \\
\text { "multicamadas", construção de narrativas. }\end{array}$ \\
\hline
\end{tabular}




\begin{tabular}{|c|c|c|c|}
\hline $\begin{array}{l}\text { Autor(es) / Ano / País } \\
\text { do estudo }\end{array}$ & Foco do estudo & Sujeitos & Método \\
\hline $\begin{array}{l}\text { Paula; Sartori; Martins / } \\
\qquad 2010 \text { / Brasil }\end{array}$ & $\begin{array}{l}\text { O conhecimento do pai acerca do aleitamento materno, as } \\
\text { orientações oferecidas à ele no pré-natal e sua participação no } \\
\text { aleitamento. }\end{array}$ & $\begin{array}{l}\text { Nove pais brasileiros com filhos de idade } \\
\text { até } 24 \text { meses. }\end{array}$ & Entrevista semiestruturada. \\
\hline $\begin{array}{l}\text { Jager; Bottoli / } 2011 / \\
\text { Brasil }\end{array}$ & $\begin{array}{l}\text { A percepção do pai sobre a volta para casa com seu bebê e as } \\
\text { implicações desse fenômeno na vida familiar. }\end{array}$ & Quatro pais primíparos brasileiros. & Entrevista semiestruturada. \\
\hline $\begin{array}{l}\text { Piazzalunga; Lamounier } \\
\text { / } 2011 \text { / Brasil }\end{array}$ & $\begin{array}{l}\text { O papel paterno durante o aleitamento materno e os fatores que } \\
\text { facilitam ou dificultam sua participação. }\end{array}$ & Doze pais brasileiros. & $\begin{array}{l}\text { Diário de campo e entrevista semiestruturada, } \\
\text { dialética. }\end{array}$ \\
\hline $\begin{array}{l}\text { Piccinini et al. / } 2012 \text { / } \\
\text { Brasil }\end{array}$ & Envolvimento paterno aos três meses de vida do bebê & Trinta e oito pais primíparos brasileiros. & $\begin{array}{c}\text { Estudo descritivo, entrevista estruturada e } \\
\text { semiaberta, análise de conteúdo temática de } \\
\text { Bardin. }\end{array}$ \\
\hline $\begin{array}{l}\text { Gonçalves et al. / } 2013 \text { / } \\
\text { Brasil }\end{array}$ & Experiência da paternidade aos três meses de vida do bebê. & Trinta e oito pais primíparos bradileiros. & $\begin{array}{l}\text { Estudo descritivo, entrevista semiestruturada, } \\
\text { análise de conteúdo temática de Bardin. }\end{array}$ \\
\hline $\begin{array}{l}\text { Williams et al. / } 2013 \text { / } \\
\text { Inglaterra }\end{array}$ & Experiência da paternidade de homens africanos migrantes. & Quarenta e seis pais africanos. & Entrevistas grupais em profundidade. \\
\hline $\begin{array}{l}\text { Poh et al. / } 2014 \text { / } \\
\text { Cingapura. }\end{array}$ & $\begin{array}{l}\text { Necessidade e experiência de pais primíparos na gestação e } \\
\text { nascimento do filho }\end{array}$ & Dezesseis pais primíparos asiáticos. & Entrevista semiestruturada, análise temática. \\
\hline $\begin{array}{l}\text { Suwada; Platin / } 2014 \text { / } \\
\text { Polônia }\end{array}$ & $\begin{array}{l}\begin{array}{l}\text { Estudo comparativo que relaciona paternidade, masculinidade e bem- } \\
\text { estar social. }\end{array}\end{array}$ & $\begin{array}{l}\text { Cinquenta e dois pais (trinta e dois } \\
\text { poloneses e vinte suecos) }\end{array}$ & Entrevista, construtivismo. \\
\hline Ives / 2014 / Inglaterra. & Transição dos homens para primeira paternidade & Onze pais primíparos britânicos. & $\begin{array}{l}\text { Estudo descritivo, entrevista face-a-face e por } \\
\text { telefone. }\end{array}$ \\
\hline
\end{tabular}


A organização, sumarização, análise crítica e integrativa das informações permitiu o estabelecimento de três temáticas tradutoras da experiência paterna ao longo do primeiro ano de vida da(o) filha(o): cuidado e interações positivas; trabalho paterno, divisão de tarefas e responsabilidades; e amamentação e paternidade.

\section{Cuidado e interações positivas}

O estabelecimento de interações com a criança apoia a vivência paterna, pois gerou sentimentos positivos, aproximou o pai da(o) filha(o) ${ }^{(12-18)}$ e teceu contraponto à sensação de desamparo vivenciada antes do nascimento da criança ${ }^{(19-20)}$. Estas interações são promovidas pelas oportunidades dos pais: participarem dos cuidados da criança; receberem apoio social; terem responsividade da criança; sentirem afinidade com ela e desejarem ser referência de valores para a(o) filha(o).

Pais brasileiros vivenciaram sentimentos de intenso prazer e realização com a concretização da paternidade ${ }^{(12,14,17,19-20)}$, sentiram-na como concretização pessoal e vivenciaram forte ligação com a criança ${ }^{(14,17)}$. Tais sentimentos vão ao encontro da verbalização de felicidade de pais suecos ${ }^{(19)}$ e asiáticos ${ }^{(16)}$ e de orgulho dos pais ingleses ${ }^{(18)}$.

Alguns homens brasileiros não conseguiram se perceber pais até o nascimento da(o) filha(o) por entenderem a gestação como um processo biológico e de encargo feminino e outros, processaram tal sentimento ao longo da gestação ${ }^{(20)}$. Houve aqueles que afirmaram estar sendo mais fácil ser pai do que imaginavam ${ }^{(20)}-\mathrm{em}$ relação ao sentimento de despreparo anterior -, pois as contribuições das experiências de familiares, $\operatorname{amigos}^{(12,15,21-22)}$ e de pessoas do local de trabalho ${ }^{(19)}$ e a facilitação da esposa na interação deles com o bebê foram significativos ${ }^{(12,14,17,20)}$. Pais de Cingapura também assinalaram os profissionais de saúde, além dos amigos e familiares, como fonte de apoio e informações ${ }^{(16)}$.

Pais brasileiros destacaram, nesta relação paifilha(o), a afinidade prévia por crianças ${ }^{(12)}$ e a reação positiva do bebê a ele como positivas ${ }^{(12,14,17,20)}$. Ainda para pais brasileiros e ingleses, o acompanhamento das rotinas do(a) filho(a) e de seu desenvolvimento e as oportunidades de aprendizado do cuidado da criança no pós parto foram promotores do senso paternal ${ }^{(12,14,17-18)}$. Nesta conjuntura, pais suecos adicionaram a maturidade pessoal ao maior envolvimento no papel paterno ${ }^{(19)}$.

As formas de interação entre os pais brasileiros e seus bebês mais citadas e quistas foram o brincar $^{(12-15,17,20-21)}$, seguido de conversar e cantar ${ }^{(12,14-15,21)}$, além de outras, como embalar no colo ${ }^{(12-13,15)}$, colocar para dormir ${ }^{(12-13)}$, passear $^{(12,17)}$ e fazer carinho(15). Em relação ao brincar, destacaram-se brincadeiras motoras e com o corpo da criança e quanto ao conversar, sobressaíram a imitação das vocalizações da(o) filha(o) ${ }^{(17)}$. Estes achados sinalizam o anseio de alguns pais pela chegada da fase verbal da criança e de outras aquisições desenvolvimentais, pois a responsividade da criança melhorou o relacionamento pai-filha(o) ${ }^{(14,19)}$. Além disso, também contribuiu a presença de semelhanças de personalidade entre o pai e a criança $^{(14)}$.

No tocante ao cuidado em saúde, os pais demonstraram preocupação com alterações físicas do corpo da criança ${ }^{(15,21)}$, aproximaram-se de seu calendário vacinal $^{(20)}$ e participaram das consultas relacionadas à saúde da mesma ${ }^{(13)}$.

Pesquisas evidenciaram que a relação pai-filha(o) foi pautada em diferenças entre os gêneros e em papéis femininos e masculinos ${ }^{(14-15,17,19)}$. Neste sentido, o pai sueco atribuiu à mãe um papel mais gentil e a ele algo de maior determinação(19). Por sua vez, o pai brasileiro relatou diferenças no seu comportamento diante da filha e do filho, quando associa o filho à tranquilidade e a filha à preocupação, especialmente em relação ao estupro ${ }^{(15)}$.

Contudo, os pais explicitaram preocupação em serem bons pais, com esforço de aproximarem-se ao máximo daquilo que prospectavam ${ }^{(17)}$ e alcançarem inserção e participação no cuidado da criança $a^{(14,16-19,23)}$, elementos da nova paternidade ${ }^{(23)}$. 


\section{Trabalho paterno, divisão de tarefas e responsabilidades}

Frente à paternidade, o senso de responsabilidade pela criança é fortemente acionado(14,17,21-22) e há participação nas decisões do cuidado da mesma ${ }^{(17)}$. Os pais demonstraram preocupação com as crianças e dedicaram-se a elas ${ }^{(14,15,17,21-22)}$. Logo, dentre as responsabilidades adotadas pelos pais, tanto brasileiros como ingleses e suecos, estão: a proteção física e emocional, prevenindo acidentes e violência, inclusive sexual $^{(21)}$; a educação, imposição de limites e o ensinamento dos bons costumes ${ }^{(15,17-21,23-24)}$; e o preparo para a vida adulta ${ }^{(17)}$. Os pais também se preocuparam com a ida da criança à creche, sobretudo em termos de maus-tratos, incipiência nos cuidados e impacto emocional e referiram sentir ciúme, saudade e insegurança ${ }^{(17)}$.

Em relação ao ato de educar, os pais esperavam que os valores transmitidos para a criança fossem retransmitidos à próxima geração ${ }^{(14-15,21,18)}$, contudo, explicitaram escolher o que transmitir ao filho, dentre o que aprendeu dos próprios pais, excluindo o que consideravam aspectos negativos ${ }^{(14,20)}$.

Outras responsabilidades paternas de brasileiros, poloneses e ingleses estiveram fortemente veiculadas a concepção do pai provedor ${ }^{(12-15,17-18,21,23,25-27)}$, como no apoio material e condições financeiras ${ }^{(12-14,17-18,27)}$, na melhoria das condições de moradia enquanto forma de proteção ${ }^{(15,21,26)}$ e na aquisição de plano de saúde como forma de cuidado ${ }^{(25)}$.

Pais ingleses ressaltaram cobrança social quanto ao papel provedor, o que determinou limites às novas paternidades $^{(18,27)}$. Estudo comparativo entre a paternidade na Suécia e na Polônia apontou que os poloneses definiram-se mais intensamente como provedores, enquanto os suecos refutaram a exclusividade deste papel. Estes últimos entenderam que a igualdade de gênero não seria alcançada sem um envolvimento dos homens na esfera doméstica ${ }^{(27)}$.

Ainda no que se refere às questões de gênero, os pais apontaram que atribuir o cuidado da criança à mulher restringiu a paternidade ${ }^{(14-15,17,19,23,25)}$. Contudo, há aqueles que reproduziram tal padrão e conceberam ser natural que a mulher desempenhe o cuidado da criança $^{(12,14-15,17,21,25,28)}$ e tenha maior responsabilidade por ele ${ }^{(14,17)}$. Estes colocaram-se como secundários/ajudantes nos cuidados ao recémnascido ${ }^{(15,25)}$ ou não dividiram igualitariamente as tarefas domésticas $^{(12)}$ e de cuidado ${ }^{(14,17)}$.

Pais britânicos relataram seguir e fazer o que a esposa determina em relação à criança, pois a mãe detém mais conhecimento sobre seus cuidados, visto que passa mais tempo com o bebê(27). Contudo, defenderam que os cuidados deveriam ser compartilhadas ${ }^{(18,27)}$, fato também sustentado por pais suecos ${ }^{(19)}$. Há ainda aqueles que apontaram ser a mãe detentora de instinto para cuidar de meninas e o pai, de meninos ${ }^{(15)}$ e outros que cuidaram da esposa por entenderem, assim, estar contribuindo para o cuidado do filho ${ }^{(25)}$. Pais asiáticos, por sua vez, apontaram mudar seus comportamentos em prol de proteger sua esposa e filho(a) ${ }^{(16)}$.

Concomitantemente, os pais relataram preocupação com o desgaste físico e emocional da companheira frente ao cuidado do bebê ${ }^{(17)}$. Alguns se disponibilizaram para assumir o cuidado durante a ausência da mãe, como no caso de intercorrências no parto ${ }^{(19)}$, em situações nas quais a mãe trabalhava ${ }^{(25)}$ ou em situações em que o pai trabalhava menor quantidade de tempo que ela ${ }^{(14,20)}$. Neste bojo, há também aqueles que não se disponibilizavam por iniciativa própria e realizavam tarefas pontuais quando solicitados, como trocar fraldas, dar banho, pegar no colo e alimentar ${ }^{(17)}$.

Estudos brasileiros listaram atividades de cuidado não quistas, desempenhadas pelos pais, tais como: trocar fraldas e/ou roupa, acalmar o filho diante de seu choro e banhá-lo ${ }^{(12,14,17)}$. Alguns sentiram-se despreparados para desempenhar o cuidado, quando há medos e inseguranças ou percepção de incompetência ${ }^{(12,14,17)}$.

Em relação ao trabalho, este integra, regula e afeta a paternidade. Dentre as preocupações com o bem-estar da criança, está a garantia da subsistência e da proteção, 
de forma que alguns pais perceberam a paternidade mais como um encargo social do que um espaço de envolvimento afetivo ${ }^{(25)}$. Nesta perspectiva, o trabalho se apresentou como o fator que mais distanciou o pai da paternidade $e^{(14-15,17-18,21-24,26-29)}$, pois diminuiu suas oportunidades de cuidado e envolvimento ${ }^{(14-15,18,23,27)}$ e restringiu contatos físicos com a criança ${ }^{(14-15,17,28)}$. Em função do trabalho, os pais afirmaram ter apenas o tempo dos períodos noturnos e dos finais de semana para investirem no convívio com o filho e participação no seu cuidado, porém relataram cansaço frente a tal dinâmica ${ }^{(14,17)}$, em especial pela interferência na qualidade do sono ${ }^{(14)}$.

Por outro lado, questões financeiras impossibilitaram que alguns pais ingleses fizessem uso da licença paternidade (visto que no país há uma remuneração menor neste período) e a volta ao trabalho fez reemergir sua identificação como provedor ${ }^{(18)}$. Ainda no que se refere a esta questão, o tempo da licença paternidade para pais brasileiros foi considerada insuficiente ${ }^{(24)}$, assim como para pais suecos, os quais usufruíram de 10 dias de licença $^{(19)}$. Porém, o entendimento da paternidade como envolvimento efetivo e afetivo, para além da concepção de provedor esteve presente em estudos com pais brasileiros, ingleses e suecos ${ }^{(17-19,20,25,27,29)}$.

Questões culturais apareceram em estudo sobre pais migrantes africanos na Inglaterra, quando estes apontaram limitações de convívio com o filho impostas por hábitos da sociedade local, ao contraporem a paternidade em vilas rurais africanas àquela vivenciada nos centros urbanos ingleses ${ }^{(22)}$.

Outra questão que está contida na experiência de ser pai são as alterações na dinâmica familiar ${ }^{(14,17)}$ e na relação do $\operatorname{casal}^{(12,14,17,19,21)}$, sobretudo em função da priorização do cuidado à criança ${ }^{(17)}$. Por vezes, há maior aproximação entre o casal $^{(12,19)}$ e em outras, sobressaem limitações em termos de liberdade, tempo e atividades sociais $^{(14)}$. Neste aspecto, pais suecos surpreenderam-se, pois foram orientados no serviço de pré-natal acerca do risco de separação do casal $^{(19)}$. E, houve situações nas quais o pai sentiu ciúme do bebê, por entender que o envolvimento da esposa com o mesmo, colocava-o em segundo plano(21), inclusive com a diminuição dos momentos do casal ${ }^{(12)}$.

\section{Amamentação e paternidade}

O processo de amamentação apresenta-se como elemento dual, podendo ser tanto um aspecto promotor da vivência paterna, como limitador.

Reforçando a historicidade sociocultural que determinou o ato de amamentar como exclusivamente feminino, a amamentação foi um dos eventos de maior impacto na sensação de exclusão do pai ${ }^{(15,17,20-21,30-31)}$ ou insignificância ${ }^{(19)}$, especialmente nos dois primeiros anos de vida da criança ${ }^{(30,32)}$.

Todavia, os pais apoiaram e incentivaram a mãe a amamentar, pois identificavam o aleitamento materno como necessário à boa saúde do filho ${ }^{(13,19,28,30-32)}$. Exerceram ações como: o amparo no posicionamento da criança $^{(19,29)}$; a obtenção de conhecimento ${ }^{(19,28,30-31,33)}$ junto às parteiras e enfermeiras pediatras, no caso sueco $^{(19)}$; a permanência ao lado da mulher propiciando um ambiente emocional favorável ${ }^{(24)}$; a atenção à mulher e ao filho ${ }^{(13)} ;$ e/ou a divisão de tarefas domésticas e do cuidado dos outros filhos ${ }^{(24,27,32)}$, em especial nos primeiros meses após o parto ${ }^{(24)}$. Além disto, pais brasileiros afirmaram que ver o filho ser amamentado pela mulher intensificou seu amor por ele ${ }^{(30-31)}$.

A falta de espaço para sua atuação no processo de amamentar motivou a busca de outros mecanismos de participação, que não os de alimentação da $\operatorname{criança}^{(32-33)}$. No entanto, sentiram-se mais próximos da(o) filha(o) e com maior espaço para cuidar da(o) mesma(o) quando ocorreu o desmame, a introdução da mamadeira e/ou inserção da criança em outros espaços sociais (além do familiar) ${ }^{(19,30,34)}$. Os pais suecos chegaram a afirmar que ao poderem usar a mamadeira sentiram-se como nutrizes, por igualmente alimentarem a criança ${ }^{(19)}$.

Acrescenta-se ainda, que no período de amamentação, as mamas foram concebidas como fonte 
de alimento do bebê, suprimindo sua imagem como órgãos sexuais e sensuais e, por consequência, contribuindo para o desmame precoce e a exclusão do pai $^{(30)}$.

Outros elementos que limitaram a participação paterna na amamentação foram a interferência das avós $^{(13)}$, a falta de informações sobre aleitamento materno $^{(33)}$ e a desvalorização da opinião do pai a respeito da mesma, fato que conduziu-o a retirar-se deste cenário $^{(28,32)}$. Ao mesmo tempo, a falta de informações e ações direcionadas aos pais suecos nas consultas de prénatal e ao longo do parto geraram incertezas e conduziram os mesmos a uma posição de tensão (alarm) $)^{(19)}$.

A vivência paterna durante o primeiro ano de vida é permeada pelas construções sociais de gênero. A socialização de gênero é entendida como o processo pelo qual homens e mulheres passam ao longo da vida e que direciona o macho e a fêmea (sex) para seus respectivos gêneros (gender) masculino e feminino. A partir das características biológicas, cada sociedade, em determinado momento histórico, constrói entendimentos (modelos) do que é próprio para cada gênero ${ }^{(35)}$.

Importante ressaltar que, por si só, esta socialização não é problemática, porém passa a representar a base das discussões atuais quando os modelos rígidos de feminino e masculino são utilizados para justificar desigualdades ${ }^{(36)}$. No contexto deste estudo, assinala-se que as construções sociais engessam homens e mulheres dentro de padrões tradicionais de pai e de mãe ${ }^{(35)}$. Logo, os mesmos mecanismos sociais que habilitam a mulher para as atividades domésticas e para o cuidado com a criança, no tocante ao homem, resultam no sentimento de medo ou despreparo vivenciado pelo pai ao manipular o bebê. Ou seja, o homem é socializado, diferentemente da mulher, para o distanciamento afetivo das(os) filhas(os) e para cumprir suas responsabilidades, que ainda estão fortemente pautadas na provisão financeira, autoridade e guardião da família ${ }^{(5)}$.
A mulher passou a integrar o mercado de trabalho, a estudar e a ter independência financeira, todavia, as mudanças no âmbito doméstico não acompanharam essas transformações e ela continuou a desempenhar seu papel socializado, mesmo em situações de dupla renda (onde ambos, homem e mulher, trabalham), o que traz repercussões a sua saúde física e emocional ${ }^{(36)}$.

Impelido que é ao ambiente público e ao trabalho, o homem não percebe o ambiente doméstico como seu local de atuação e também não está familiarizado com os cuidados à criança e os afazeres domésticos ${ }^{(35)}$. Portanto, para encontrar seu lugar na dinâmica familiar, o pai precisa se interessar e buscar informações, seja com amigos, familiares ou colegas de trabalho. Do mesmo modo, sua atuação depende da permissividade da mulher ou da indisponibilidade dela exercer tal função.

Além disso, o apelo da sociedade para que o homem proveja o lar e a necessidade de passar tempo no trabalho, bem como a inexistência de políticas públicas que possibilitem ao pai usufruir do convívio com a criança após seu nascimento demarcam o trabalho como um elemento prioritário na regulagem do envolvimento paterno com a família e criança. A concepção de provedor segue presente em todos os contextos encontrados pela revisão, o que ampara o caráter universal desse entendimento.

A exclusão do pai também ocorre durante a amamentação, quando ele vivencia sentimentos de desvalorização ou insignificância. Em primeira instância, o aleitamento é entendido pelo pai, pela mãe e pelo entorno como um ato fisiológico e exclusivamente feminino e, portanto, permeado por uma construção sociocultural que não provê ao pai as competências e habilidades necessárias para participar da amamentação. Competências socialmente atribuídas à mulher, o que, contudo, não significa que amamentar seja um ato inato à ela, questão claramente discutida por outros autores ${ }^{(37-}$ ${ }^{38)}$. Outro aspecto analisado é a valoração romanceada do vínculo mãe-bebê no aleitamento materno, ao mesmo tempo em que o homem não recebe o mesmo valor ${ }^{(38)}$. 
Neste contexto, vale exaltar ainda que o pai pode ansiar o termino do período de aleitamento e a introdução da mamadeira - que traz consequências para a duração do período de amamentação da criança -, a chegada da fase verbal ou a introdução da criança nos espaços públicos para, assim, poder ocupar mais espaço na vida dela.

A assunção da responsabilidade do pai como um encargo social apresenta-se, expressivamente, com a concretização da paternidade e a cobrança pelo sustento material. Entretanto, muitos pais demonstram insatisfação como essa única e exclusiva relação com a paternidade e a têm vivenciado de forma mais ampla e participativa. Tal fato pode ser constatado pela expressão de sentimentos positivos quanto à paternidade, pelo interesse do pai pelo filho e seu cuidado, pela divisão dos afazeres domésticos e dos cuidados com a criança e por sua aproximação da amamentação, quando exerce apoio à mãe. Assim, amplia-se o escopo de atuação do pai, possibilitando oportunidades de (co)protagonizar os cuidados domésticos e da criança e de criar as habilidades necessárias para tanto ${ }^{(38-39)}$.

No entanto, tal processo ocorre sob uma historicidade e persistência dos padrões tradicionais de masculino, remetendo o a revisitar tal modelo, imergindo e reemergindo nos diferentes entendimentos de ser pai, conceitos, ora estendidos, ora atrelados ao ideário social de provedor. Percebe-se ainda que os próprios entendimentos são dinâmicos e estão na dependência de distintos aspectos. Logo, compreende-se a coexistência de múltiplos modelos de pais, tanto no Brasil, como em outros países, cujos estudos formaram o corpo desta revisão.

\section{CONCLUSÕES}

A paternidade durante o primeiro ano de vida do(a) filho(a) é vivenciada pelo pai de forma paradoxal, pois a medida que alcança um novo status quo na sociedade e almeja estar perto da criança, precisa opor-se a um contexto de cobrança e imposição restrita à função de provedor financeiro e guardião da família.

Deste modo, vivenciar novas paternidades demanda um embate entre os desejos do pai e valores sociais, num contraponto que também põe em questão o modelo de masculinidade, as exigências da família moderna e as características intergeracionais. Assim, a ascensão do novo pai exige um novo homem, capaz de entender e repensar seus caminhos. A emergência de um novo pai necessita de uma mãe sensível às necessidades do seu companheiro e proativa no estímulo a sua participação no cuidado da criança.

Os achados aqui apresentados contribuem para a ampliação de referenciais na temática da paternidade e gênero, com vistas a consolidar a travessia para novas paternidades. Aponta também a necessidade de desenvolvimento de estudos na Saúde voltados às novas paternidades, uma vez que esta revisão utilizou um recorte muito específico. Muitas lacunas ainda precisam ser estudadas para avançar a construção do conhecimento acerca desta temática, como por exemplo, as nuances do cuidado paterno nos casos em que o pai não coabita com o filho; as relações permeadas por contextos de violência, adoecimento, encarceramento, etilismo, entre outras. Além disso, faz-se necessário ampliar as discussões para estratégias educativas exitosas em saúde que possam aproximar o pai do cenário doméstico e superar padrões de gênero que perduram no imaginário social.

2. Cúnico SD, Arpini, MD. The family in change: challenges for contemporary fatherhood. Pensando Fam. 2013;17(1):28-40. 3. Júnior EG, Feijó MR, Cunha EV, Corrêa BJ, Gouveia PAES. Family and work requirements: a necessary equilibrium for 
worker and organization health. Pensando Fam.

2013;17(1):110-122.

4. Badinter E. Um amor conquistador: o mito do amor materno. 9ed. Rio de Janeiro: Nova Fronteira, 1985.

5. Toneli MJF, Araújo SA, Amaral MS, Silva FLS. Exercícios e atribuições da paternidade: pequeno balanço de uma década de pesquisa. In: Toneli MJF, Medrado B, Trindade ZA, Lyra J, editors. O pai está esperando? Políticas públicas de saúde para a gravidez na adolescência. Florianópolies: Ed. Mulheres; 2011. p. 125-148.

6. Brito GF, Paula JV. The masculinity and the ideology: the masculine socialization. OPSIS. 2013;13(2):173-88.

7. Arilha M. Homens, Saúde Reprodutiva e Gênero: o desafio da inclusão. In: Giffin K editor. Questões da saúde reprodutiva. Rio de Janeiro: Editora Fiocruz; 1999, p.455-467.

8. Ríos 0 , Christou M. Más allá del lenguaje sexista: actos comunicativos en las relaciones afectivo-sexuales de los y las adolescentes. Signo. 2010;43(2):311-326.

9. Meyer DE, Klein C, Fernandes LP. Noções de família em políticas de 'inclusão social' no Brasil contemporâneo. Rev. Estud. Fem. 2012;20(2):433-49.

10. Whittemore $R$, Knalf $K$. The integrative review: updated methodology. J Adv Nurs. 2005;52(5):546-53.

11. Menezes KDS, Silveira RCCP, Galvão CM. Revisão

integrativa: método de pesquisa de incorporação de evidências na saúde e na enfermagem. Texto Contexto Enferm.

2008;17(4):758-64.

12. Krob AD, Piccinini CA, Silva MR. Transition to fatherhood: from pregnancy to the second month of life of the baby. Psicol. USP 2009;20(2):269-91.

13. Piazzalunga CRC, Lamounier JA. The current role of the father in the breastfeeding process: A qualitative approach. Rev Med Minas Gerais. 2011;21(2):133-41.

14. Gonçalves TR, Guimarães LE, Silva MR, Lopes RCS, Piccinini CA. Fatherhood experience in infant's third month. Psicol. Reflex. Crit. 2013;26(3):599-608.

15. Bustamante V. Being a father in the railroad suburb of Salvador: a study case with men from popular classes. Psicol. Estud. 2005;10(3):393-402

16. Poh HL, Koh SSL, Seow HCL, He H. First-time fathers' experiences and needs during pregnancy and childbirth: A descriptive qualitative study. Midwifery. 2014;(30):779-787. 17. Piccinini, CA et al. Fathers' involvement during the baby's third month. Psic.: Teor. e Pesq. [online]. 2012[acesso em: 18 out 2013];28(3):303-314. Disponível:

http://www.scielo.br/scielo.php?script=sci_arttext\&pid=S0102 -37722012000300006.

18. Miller, T. “It's A Triangle That's Difficult To Square": men's intentions and practices around caring, work and first-time fatherhood. Fathering. 2010;8(3):362-378.

19. Fagerskiöld A. A change in life as experienced by first time father. Scand. J. Caring Sci. 2008;(22):64-71.

20. Silva MR, Piccinini CA. Feelings concerning fatherhood and fathers' involvement: a qualitative study. Estud. Psicol.

(Campinas). 2007;24(4):561-73.
21. Bustamante V, Trad LAB. Paternal involvement in the care of small children: an ethnographic study of low-income families. Cad. Saúde Pública. 2005;21(6):1865-74.

22. Williams B, Hewison A, Wildman S, Roskell C. Changing Fatherhood: An Exploratory Qualitative Study with African and African Caribbean Men in England. Children and Society. 2013;27(2):92-103.

23. Jager ME, Bottoli C. Paternidade: vivência do primeiro filho e mudanças familiares. Psicologia: Teoria e Prática.

2011;13(1):141-53.

24. Freitas WMF, Coelho EAC, Silva ATMC. Fatherhood: the male experience from a gender focus. Cad. Saúde Pública. 2007;23(1):137-45

25. Freitas WMF, Silva ATMC, Coelho EAC, Guedes RN, Lucena KDT, Costa APT, et al. Paternity: social responsibility of man's role as provider. Rev. Saúde Pública. 2009;43(1): 85-90.

26. Henwood K, Procter J. The 'good father': Reading men's accounts of paternal involvement during the transition to firsttime fatherhood. British Journal of Social

Psychology.2003;(42):337-355.

27. Ives J. Men, maternity and moral residue: negotiating the moral demands of the transition to first time fatherhood. Sociology of Health \& Illness. 2014;(36):1003-1019.

28. Oliveira EMF, Brito RS. Actions in care carried out by father in the puerperism. Esc. Anna Nery Rev. Enferm.

2009;13(3):595-601.

29. Suwada K, Plantin L. On Fatherhood, Masculinities and Family Policies in Poland and Sweden: a comparative study. Polish Sociological review. 2014;4(188):509-524.

30. Pontes CM, Alexandrino AC, Osório MM. The participation of fathers in the breastfeeding process: experiences, knowledge, behaviors and emotions. J. Pediatr. (Rio J.) 2008;84(4):357-64.

31. Brito RS, Oliveira EMF. Opinião do pai sobre aleitamento materno. Rev. RENE. Fortaleza. 2006;7(1):9-16.

32. Pontes $\mathrm{CM}$, Osório MM, Alexandrino AC. Building a place for the father as an ally for breast feeding. Midwifery. 2009;25:195-202.

33. Paula AO, Sartori AL, Martins CA. Breastfeeding: father's orientations, knowledge and participation in the process. Rev. Eletr. Enf. [Internet]. 2010 [acesso em: 05 out 2012];12(3):46470. Disponível em:

http://www.fen.ufg.br/revista/v12/n3/v12n3a07.htm.

34. Bucher-Maluschke JSNF. Father who care for their children: the male experience of participatory fatherhood. PSICO.

2008;39(1):74-82.

35. Whitaker D. Homens e mulheres: o mito da desigualdade. Mulher \& Homem: o mito da desigualdade. 7th ed. São Paulo: Editora Moderna, 1988.

36. Gomes AJS, Resende VR. O. The present father: discovering the fatherhood in a contemporary family. Psic.: Teor. e Pesq. 2004;20(2):119-25.

37. Souza SNDH, Mello DF, Ayres JRCM. Breastfeeding from the perspective of programmatic vulnerability and care. Cad. Saúde Pública [Internet]. 2013 Jun [citado 2012 Out 10];29(6):11861194. Disponível em: http://dx.doi.org/10.1590/S0102311X2013000600015. 
38. Resende TC, Dias EP, Cunha CMC, Mendonça GS, Junior $A L R$, Santos LRL et al. Father participation in the period of breastfeeding: importante and contribution. Biosci J.

2014;30(3):925-32.

39. Santos ND, Machado MED, Christoffel MM. (Re)cognizing the masculine participation in kangaroo method: an interface with the assisten. Cienc Cuid Saude. 2013;12(3):461-8. DOI:

10.4025/cienccuidsaude.v12i3.11722.

Recebido: 04/04/2014.

Aceito: $16 / 04 / 2015$.

Publicado: 30/09/2015. 